\title{
THE INTEREST IN LEARNING MARXIST - LENINIST PHILOSOPHY OF HANOI UNIVERSITY OF SCIENCE AND TECHNOLOGY NON-POLITICS MAJORED STUDENTS: SITUATION AND SOLUTIONS
}

\section{Xuan Thanh Dinh}

\section{Article History}

Received: August 16, 2020

Accepted: September 10, 2020

Published: September 30, 2020

\section{Keywords \\ Interest, interest in learning, Marxist Leninist philosophy, non-politics majored students, Hanoi University of Science and Technology}

\author{
Hanoi University of Science and Technology, Vietnam \\ Email: xuan.dinhthanh@hust.edu.vn
}

\section{INTRODUCTION}

Interest is defined as an individual's special attitude towards a certain object. It is meaningful to life and able to generate motivation in different activities. Interest manifests itself in high concentration on and fascination in the content as well as the scale of those activities. Interest gives rise to aspiration to act, increases efficiency of cognitive activities and working capacity.

Learning is one of the most important tasks of students and interest in learning plays an essential role in improving the effectiveness of learning processes, enables students to enhance their attention and creativity. Interactive learning develops activeness as well as the desire to explore knowledge.

The article investigates and evaluates the current situation of learning interest in the Marxist-Leninist Philosophy among HUST students, thereby proposes some solutions to help students be more engaged in learning the subject, with the aim to achieve the course objectives in a sustainable way.

\section{LITERATURE REVIEW}

As Sacdacob (1970, p.9) points out in his work "Students' thinking", "Interest is one of the internal conditions of thinking, making thinking a willful, purposeful process and sometimes full of enthusiasm and excitement".

Marcova (1976) studies the role of problem-solving teaching with students' interest in learning: "Problem-solving teaching is one of the important measures that contribute to improving students' interest in the learning process".

According to Nguyen Khac Vien (1991, p.122) in Psychological Dictionary, "interest is an expression of one's desire to find a way to satisfy oneself, creating pleasure and enjoyment. Talking about interest is talking about goals, mobilizing energy (physical and psychological) to work hard. There are immediate pleasures such as the appetite to eat something; and interests fulfilled indirectly through other activities, in most cases uninteresting ones, such as studying math to pass the end-of-term exam. Interest causes the subject act".

Nguyen Quang Uan \& Tran Trong Thuy (1998, p.187) in General Psychology researches the concept of interest: "Interest is an individual's special personal attitude towards a certain object, both meaningful to life and capable of creating emotions to the individual in the cognitive process".

Thai Duy Tuyen (2008b), in Traditional and Innovative Teaching Methods, analyzes problems of traditional and modern teaching methods, and urgent issues in innovating teaching methods. As he affirms, "Interest is the unity between the inner nature and the objective world. (...) Interest is not an independent and closed process, but must be derived from surrounding natural and social life. If we change our living conditions, our interest can change. That means interest can be controlled. (...) What teachers have to do regularly is stimulating interest in the teaching process...".

Thai Duy Tuyen (2008a, p.285) in "Modern Education (the basic contents)" states that "The teacher can monitor the interest of students through the elements of the teaching process: content, methods, means of organization, 
teaching steps: Introducing lessons, giving lectures, consolidating, applying, testing knowledge; through the relationship between teachers and students...".

Tran Ba Hoanh (2002, p.26) in "Characteristics of Active Teaching Methods", Journal of Education No. 32 confirms that "cognitive positivity in learning activities is related firstly to learning motivation. The suitable motivation generates interest. Interest is the premise of self-consciousness. Interest and self-awareness are two psychological factors that create positivity".

Nguyen Thu Cuc (2003) in "Learning Excitement and Interest in Learners" published in the Journal of Education analyzes the concept of interest, interest in learning and classifying interest in learning into two categories: direct interest and indirect interest in learning activities, at the same time presents three criteria for expression of interest.

Nguyen Hoai Sanh (2011) in "The Problem of Creating Interest for Learners when Teaching Philosophy and Political Theory Subjects" in the Journal of Education No. 255 points out the major factors that affect learners' interest in learning such as cognitive capacity, learning motivation, determination, learning environment, and teaching process organizers and at the same time offering some solutions for teachers to create interest for learners such as: linking the lessons with real life; taking the leading roles in the class; creating a delightful and stress-free classroom atmosphere...

Nguyen Van Cu (2007, p.94) in the Curriculum of Scientific Socialism mentions teaching methods that create interest in learning for students in scientific socialism teaching in Vietnam: "Using teaching facilities will help teachers impart a large amount of rich updated knowledge to students. Consequently, the teacher will attract students to participate in the process of learning about scientific socialism and the process of building socialism in Vietnam today".

Nguyen Van $\mathrm{Cu}$ (2007, p.118) also points out: "The use of television is particularly effective in transmitting knowledge about politics, economy and culture - society. It helps improve the teaching of general Marxist courses as well as particular subjects, making teaching more attractive to the learner."

There are also a number of articles about teaching methods that create interest in civic education by Nguyen Van $\mathrm{Cu}$, Nguyen Le Thu, Nguyen Quang Uan, etc. Thus, it is clear that there has been a considerable amount of basic research on learning interests in general. However, there are only few studies on the interest in learning MarxistLeninist Philosophy, and this gap apparently needs further investigation.

\section{RESEARCH METHODS AND RESULTS}

\subsection{Research method}

The research used descriptive methods to find out the level of interest in learning the Marxist-Leninist philosophy of HUST students and the factors that influenced their interest in learning. The 500 participants surveyed in this study are students from 6 disciplines being trained at HUST including: Information Technology, Electrical, Mechanical, Electronics and Telecommunications, Management Economics, and Foreign Languages.

Descriptive methods facilitate the illustration and explanation of the situation under investigation. In this study, it is used to describe the survey participants' profiles and their perceptions of the factors that influence their interest in studying Marxist-Leninist philosophy at HUST.

The data collection tool employed in this research is a two-part questionnaire that covers personal information and factors that influence the interest in learning the Marxist-Leninist philosophy of HUST students.

The collected data is described statistically using percentages, the percentage of respondents' profiles, and factors that influence the students' interest in learning the subject.

\subsection{Research results}

\subsubsection{Factors affecting students' interest in learning and the signals of learning interest among students}

\subsubsection{Factors affecting students' interest in learning}

Interest in learning has great significance to students' achievement and learning outcomes. It plays a particularly important role in improving the effectiveness of learning processes, whereby students can reduce fatigue and stress, increase attention, and promote positivity and creativity. There are many factors that influence the formation and development of students' interest in learning, but basically these can be divided into two basic elements:

- Subjective factors: students' interest in learning is influenced by many different factors, in which learners as subjects of cognitive activities are considered the decisive factor to the level of interest for learning while lecturers fundamentally affect the subject of this cognitive activity.

- Objective factors, including: 
+ Intra-discipline factors: the subject content influence students' interest in learning regarding the relevance of these contents to their self-awareness, the practicality with the major as well as the topicality, thereby impacting students' learning motivations.

+ School-related factors: facilities and technical appliances are fundamental to teaching and learning activities, wielding certain influence on students' interest. If the demand is not met, the activeness and enthusiasm of students for learning activities will definitely be reduced.

+ Lecturers-related factors: The most important factor that generates engagement or disinterest among learners is closely related to the teacher, particularly to their teaching methods, lectures and 'art' in class. The key is to "simplify" philosophical knowledge by bringing academic and philosophical knowledge closer to real life, making it easier for learners to understand. The lecturer has to make learners understand that Marxist philosophy really is a philosophy of life that is useful for life and useful for people (Nguyen Hoai Sanh, 2011).

Hence, along with professional knowledge, the pedagogical approach of teachers is also a factor that strongly affects students' learning interest. If the instructor can present a problem that requires thinking and exploring in each lesson, this will create a passion for students. Teachers' teaching methods have to be appropriate to physiological and cognitive characteristics as well as the learning content, always focusing on problematic situations to stimulate learning interest, thinking ability and creativity. This combination of soft skills such as critical thinking, teamwork and presentation skills in the teaching process will also promote students' interest in learning where they can actively work, "brainstorm" and partake. On the other hand, teachers' attitude towards students (fair assessment, open communication) also has a strong influence on students' interest in learning, enhancing their self-confidence in their cognitive ability. Self-confidence in communication will promote the interest of learning among students.

As for Marxist-Leninist philosophy - a challenging and abstract general subject, it is crucial for learners to develop an interest in studying. Regarding philosophical knowledge, one might not be able to recognize its practical value in explaining real-life phenomena and directing actions if they do not comprehend its principles and rules. For this reason, students might not like or be interested in the subject. Therefore, detailed investigation into the concepts, rules, categories and principles to understand the nature of the matters as well as associate this with practical relationships, applying the world view and the learned methodology to solve problems is extremely important in helping students become more interested in learning.

3.2.1.2. The signals of learning interest

To measure the interest in studying Marxist-Leninist Philosophy, among students in general and HUST students in particular, it is necessary to base this assessment on groups of signals such as behavior and activities of learners in and outside the classroom, their points of view or lifestyle under the influence of learning interest. Typical features of behaviors and classroom activities are positive thinking, attentiveness and active participation in discussions on the issues raised by the instructor. Once interested, the learner tends to examine the nature of the problem and knowledge, entailing questions and answers to arise. In addition, interest in learning is also reflected in specific learning activities at home such as reading books, using reference materials, sharing ideas with instructors and peers.

Interest in learning can be expressed in students' attitude towards the subject, such as their perception of the importance and the practical meaning of the subject to their major and life. Students find themselves interested in the subject, satisfied with the instructor and the knowledge provided after each lesson.

\subsubsection{The current state of interest in learning Marxist-Leninist philosophy of HUST non-politics majored students}

As a learning technology institute in Vietnam, HUST students all are required to take the compulsory course of Marxist-Leninist Philosophy as a general course. To objectively examine the state of learning interest in MarxistLeninist Philosophy among HUST non-politics majored students in the current period, the author surveyed nearly 1,000 HUST students, mainly in the first year (K62), who have just completed the course and second-year students (K61), who had to re-take this course. In response to the question "Do you have an interest in studying MarxistLeninist Philosophy?", around 63\% of the students respond with 'no'.

- Signals of behaviors and learning activities in the classroom: As shown in the collected data, more than half (about 55\%) of the survey participants believe that the lectures are interesting and relevant to their real life. A little lower percentage ( $45 \%$ ) confesses that they only attend lectures for high scores, with very little concentration because of difficult, monotonous and tedious content. This disinterest certainly affects the achievement of the learning goal.

In response to the question "While attending lectures of Marxist-Leninist Philosophy, do you ask any questions?", around $77 \%$ says that they seldom or never ask the lecturer. This figure reveals an alarming fact that a substantial 
number of students show little or no interest in the subject with numerous abstract contents even though they are well aware of its importance compared to other subjects.

The next question addresses "How important do you think Marxist-Leninist Philosophy is in the undergraduate curriculum?" and $88 \%$ of the respondents think that this is as important to HUST students as other required courses.

According to the data on students' involvement in discussion periods, $40 \%$ prepares as required by the teacher with no interest, and even 5\% skips these sessions.

- Signals of behaviors and learning activities after class: The sustainability of learning interest is displayed in how often learners read more books and materials related to the subject, whether they plan to use free time to meet the requirements of the subject. In answer to the question "Do you consult relevant materials while studying MarxistLeninist Philosophy?", about 77\% of the respondents admit that they only sometimes or never read textbooks or materials related to the course.

On being asked if they prepare for the discussion before class, only about $28 \%$ are consciously ready while $52 \%$ occasionally and about $20 \%$ come unprepared.

To promote students' interest in Marxist-Leninist Philosophy, there should be additional activities outside the classroom such as organizing student clubs and Olympic-like contest about Marxist-Leninist Philosophy and Ho Chi Minh ideology, scientific research workshop for students, etc. Responses to the question of "Which activities help develop your interest in study Marxist-Leninist Philosophy?" show that about 47\% favor a club in philosophy, another 24\% prefer scientific research workshops, $15 \%$ support an Olympics contest, and the remaining $14 \%$ have different opinions. These seems to be effective measures to increase students' learning interest in these courses.

\subsubsection{Causes of the current level of learning interest in Marxist-Leninist Philosophy course of non-politics majored} students

The causes are based on two main categories: subjective (the students) and objective (the subject content, the school, and the teacher).

- Subjective reasons: According to the survey results on what changes should be made to improve students' interest in learning Marxist-Leninist Philosophy, most students believe that they have to change their attitudes and learning routines: being more serious, hard-working, self-aware and interactive with teachers and classmates. Some further suggestions are spending more time reading materials at home and being attentive to lectures in class.

- Objective reasons: It is undeniable that all objective causes can be attributed to the teacher, as whether the subject content or the school is involved finally depends on the teacher. This finding is consistent with the results of the survey: $89 \%$ of the student participants say that the lecturers' teaching methods affect their interest in learning. The result also reflects the same principle in education: for the same content, a proper teaching method will derive positive effects, contributing to students' progress and improvement of excitement in learning the subject.

According to the collected data, 55\% of the respondents think that the method that combines presentations with conversations is one solution to the problem of disinterest among students in studying the module. This result is perfectly suited to the specificity of the subject. Marxist-Leninist Philosophy is a very abstract subject, so to clarify the concepts, categories and rules, pure presentations will lead to monotonous lectures which make students become passive and distracted. Meanwhile, a combination of lecturing and conversing will not only clarify the content of the knowledge but also keep students in an active state during the lecture. Students in these lessons have to stay attentive in order to ask and answer questions raised by the lecturer and peers, thereby increase their comprehension as well as enjoyment.

\subsubsection{Some solutions to enhance the interest in learning Marxist-Leninist Philosophy}

Within the scope of the topic, the author concentrates on two main solutions to enhance students' interest in learning Marxist - Leninist Philosophy in the current period. These two solutions are related to the renovation of teaching methods on the basis of the material conditions. Firstly, there should be an inclusion of "soft skills" training in teaching. Secondly, Blended-learning (B-learning) should be applied.

3.2.4.1. Combining "soft skills" training in teaching to generate an interest in learning Marxist-Leninist Philosophy for current students

It is well admitted that tertiary education both meets a social orientation and provides human resources to meet the requirements of the labor market. In the present context, the pressure on universities is even greater when the teleconferencing program requires highly qualified teachers with interdisciplinary as well as other skills such as awareness of issues related to criticism, analysis, synthesis, systematic thinking, creativity, self-study, real and virtual worlds, group work, collaborative grouping etc (Lai The Luyen, 2015). Therefore, university subjects in general and 
Marxist-Leninist Philosophy in particular have to accomplish numerous objectives: not merely to practice political stability, patriotism, and loyalty to the goal and ideals of national independence associated with socialism, fostering revolutionary moral qualities, etc but also to train skills for students to be able to meet the requirements of the labor market in the current context such as: + Self-study skills; + Communication and behavioral skills; + Presentation, group work, critical thinking, synthesis, assessment and creation skills; + Research skills.

The curriculum of Marxist-Leninist Philosophy includes basic issues such as materialism, consciousness and the relationship between them. In details, there are two principles, three basic rules, six categories of materialism; theories of dialectical materialism,... (Ministry of Education and Training, 2006, 2014). To clarify the connotation of concepts, categories and the content of abstract rules, lecturers need to combine presentation methods with conversations. Slides supported by images will enhance learning interest. Lessons are delivered in an active and comfortable atmosphere with suitable level of difficulty while students are trained with communication and behavioral skills.

Well organized seminars of the module are very important to help students understand the very abstract content of Marxist-Leninist Philosophy, especially the conclusive methodological principles.

To organize a good discussion session, students will be divided into groups to fulfill some topic-based requirements beforehand. For each group, the presenters elaborate their assigned topic in class while the others answer the questions raised by peers or lecturers. In this process, the instructor will encourage other groups to ask critical, synthesized, and creative questions (bonuses might be applied). Thereby, students can practice skills of critical thinking, synthesis, evaluation, creativity, presentation, teamwork, communication, and behavior.

For example, the discussion topic can be: Adam Khoo's book "Mastering the Changing Mind of Mind" and the dialectical relationship between materiality and consciousness. To prepare for the in-class discussion, students must understand the essential dialectical relationship between materialism and consciousness based on the understanding of the material category, the origin of life and the nature of consciousness, how the material has a role and how decisive it is in relation to consciousness, the immense impact of consciousness in transforming the physical world through human practice. Methodological meaning is drawn from this relationship, especially the principle of promoting subjective dynamism. Students must also read the book, and these tasks are clearly assigned in the group: the team leader, the secretary, the presenters, and the members who clarifies the lesson content: The viewpoint on dialectical materialism of material, consciousness, the relationship between material and consciousness. During the discussion which is recorded for further reference, the presenters elaborate the lesson content, after which some questions could be raised such as "Materialism determines consciousness. So, does it mean that rich people are happy? Is the country with the highest happiness index in the world the richest country in the world?" "Materialism determines consciousness, so why can consciousness exert a strong impact on the physical world? How does consciousness return the effect to the physical world? Does "thought mastering to change destiny" mean that materialism depends on consciousness?" To answer these questions, students have to grasp the core content and practice critical thinking, evaluation, synthesis, and creation. Through such discussions, they will gradually develop their interest in the subject, the dull content will get closer to the real life thanks to hands-on experience.

For the assessment of the process, teachers could organize reflection session in which students write essays in groups with assigned topics. This form of formative assessment is an opportunity for students to train writing and scientific research skills as well as to gain team work experience. This activity evaluates not only the performance of the whole group, their preparation prior to the lesson and their essays but also the groupwork process (assigning tasks to individuals, carrying out tasks, submitting essays, preparing the discussion, etc.).

\subsubsection{Using Blended-learning (B-learning) in Marxist-Leninist Philosophy teaching for students}

The trend of development in science and technology as well as in information technology (IT) requires suitable teaching methods in general education and training (Resolution No. 26/NQ-CP of the Government). The use of Blended learning (B-learning) in the teaching of the subject in question will contribute to the enhancement of students' interest in learning and improving the effectiveness of teaching.

Blended-Learning (combination teaching or blending learning) is a combination of traditional learning models where learners and teachers are in direct contact with each other and models of online learning so that they are mutually supportive. Blended-Learning (B-Learning) creates opportunities for individuals to take the best advantages of both models. It potentially creates more time for individual teachers and helps students personalize their learning inside and outside of school (Atkins, S.S. 2016). B-Learning tools and support platforms are learning management 
systems (LMS) and mobile devices such as tablets and smartphones, so the concept is used in the field of education to describe a learning program that combines classroom interaction and the application of technology in teaching and learning. For most of the time, lessons combining this approach still take place in the classroom with the teacher's guidance (like other traditional methods) but take full advantage of technology in education. As a result, this helps to improve the learning experience and results.

Regarding the B-learning in teaching Marxist-Leninist philosophy, the blended face-to-face model (face-to-face instruction combined with electronic devices with Internet connection) is the most suitable. Because of the theorybased essence of Marxist-Leninist Philosophy, $70 \%$ of the class hours is for theories and 30\% for discussion. During the $70 \%$ theoretical period, students are introduced with general information of the module: syllabus, schedule, group discussion and essay writing, then listen to online lectures, discuss online through case studies, and practice through multiple choice questions. On a weekly basis, students only go to class on a fixed schedule to discuss the theoretical content learned during that week.

Two main principles associated with integrated teaching methods as the decisive factor for the success of this teaching model are learners' information sharing and cooperating directly with others to have a more productive learning experience. Collaboration between different learners will be more effective if group activities are based on information gathered from online materials or lessons. At the same time, learners who complete online courses in combination with interactive and direct activities in class will have better learning experiences. Therefore, it is very important to conduct well-organized class discussions on the subject matters, to help students understand theoretical issues as well as knowledge, gradually apply them in solving real-life problems. Once recognizing how meaningful the subject is, students will grow a passion for it. This blended teaching and learning model also brings many other benefits, generating more motivation and interest among students in studying the subject, such as:

- Greater flexibility: The application of technology in Marxist-Leninist Philosophy syllabus allows students to fully master the process of theoretical study and choose the schedule that fits their personal timetables. Learners will have a separate learning account and can freely choose the time, location, duration of study and equipment to support their learning.

Due to social, cultural, economic and political changes, students currently require more flexibility in learning. In other words, the current flexibility in learning is essential in order to meet the need for a balance between learning and life.

- More autonomy: The use of B-learning in teaching Marxist-Leninist philosophy helps to increase autonomy among learners. For students the autonomy in time, place and content means greater and more effective control over their own learning. They will also develop a higher sense of responsibility and self-discipline, thereby improving their ability to find materials and resources to achieve their learning goals, and adjusting the individual learning speed.

As learning programs and applications can now be accessed online $24 / 7$, blended learning enables students to study at their own speed, thereby having more time to master, accomplish and review completed activities. Besides, the freedom to choose the right time for learning also provides optimal learning outcomes.

- More feedback: Online and in-class discussions as well as responses to multiple choice questions are forms that help teachers analyze more quickly about the activities performed, comment and evaluate students' competences more effectively. This helps them adjust the teaching methods and feedback for students while the effectiveness of time is still improved. Feedback from teachers helps learners realize their strengths and weaknesses, allowing them to make more choices about their learning needs. For some activities that apply integrated learning methods, teachers can even give immediate feedback, improving the effectiveness of this process.

- Better interaction between learners and teachers: Although technology in education offers enormous benefits, interaction between students and lecturers still plays an important role, especially in combined learning where both lecturers and students gain valuable knowledge in the learning process. For Marxist-Leninist Philosophy courses, the interaction between students and teachers during discussion sessions will help teachers to assess students' understanding, quickly helping students realize their strengths and weaknesses for future progress. At the same time, presentation, criticism, effective communication, and teamwork skills are trained.

- Improved learning outcomes: As combined learning helps students better control the time, location and pace of learning, their motivation is improved. Learners will also have more time to complete assignments in the optimal conditions, helping them stay focused and improve their learning outcomes. As a result, they are more likely to grow their interest in studying the subject. 
As students' competences, learning conditions and methods are now different, changes should be made to education and training in order to meet the new demands. Proper learning models that suit individual students will help improve their interest as well as the quality of teaching. A combination of technology and classroom interaction will ensure an improvement in the quality of teaching as well as students' participation, autonomy and enjoyment. It also allows us to continually adapt to the needs and interests, of $21^{\text {st }}$-century students. However, it should be noted that universities maintain traditional teaching methods in the teaching of Marxist Philosophy and only employ Blearning in this model to meet their learning needs rather than apply a rigid model for all students.

\section{DISCUSSION AND CONCLUSION}

Promoting interest in studying Marxist-Leninist Philosophy in HUST has a great significance in the current time, as only when students are interested in learning, can the course objectives be achieved sustainably.

It is revealed that in Marxist-Leninist Philosophy courses, level of learning interest among students is still quite high. This situation can be put down to two main reasons, subjective and objective, related to the subject, the school and the lecturer. But from the perspective of the educator, the underlying cause is primarily the lecturer, especially thanks to their teaching methods.

The situation analysis within the framework of a university-level research project also suggests two specific solutions. However, in order to implement these solutions well, the author has some suggestions as follows:

- From the university's perspective: There should be no more than 150 students per class for theoretical lectures; the discussion time should not exceed 50 students per class; Computers and Internet connection in classrooms should be improved; the university should assist the Faculty to organize the Olympics-like contests and student clubs focusing on Marxist-Leninist Philosophy.

- From the lecturer's perspective: It is important to constantly study and improve their professional skills so that they can use modern teaching methods and means.

- From the student's perspective: Although two measures above are very necessary to develop students' interest in learning Marxist-Leninist Philosophy, students play the decisive roles in creating learning interest for themselves. Passion and love for the subject are the key to the willingness and readiness to learn and overcome all obstacles to achieve outstanding outcomes. Therefore, this great internal resource in each student can be replaced by no one or nothing else.

\section{REFERENCES}

Atkins, S. S. (2016). The 2016-2021 worldwide self-pace E-Learning Market: Global E-Learning market in step decline. Ambient Insight.

Lai The Luyen (2015). Soft skills and success. Hong Duc Publishing House.

Marcova A. K. (1976). The role of problem-solving teaching in students' learning interest. Hanoi Education Publishing House.

Marcova A. K. (1989). Cognitive Awareness - Teachers' Handbook (translated by Nguyen The Hung). Knowledge Publishing House.

Ministry of Education and Training (2006). Marxist-Leninist Philosophy. National Political Publishing House.

Ministry of Education and Training (2014). Basic Principles of Marxist Leninism. National Political Publishing House.

Nguyen Hoai Sanh (2011). The issue of creating interest for learners when teaching philosophy and political theory subjects. Vietnam Journal of Education, 255, 49-50; 53.

Nguyen Khac Vien (1991). Psychological Dictionary. Hanoi Foreign Literature Publishing House.

Nguyen Quang Uan, Tran Trong Thuy (1998). General Psychology. Education Publishing House.

Nguyen Thu Cuc (2003). Interest and learning interest among learners. Vietnam Journal of Education, 56, 15-17.

Nguyen Van Cu (2007). Teaching methods of scientific socialism. Hanoi Pedagogical University Publishing House.

Pham Minh Hac (2005). Psychology. National Political Publishing House.

Sadacob M. N. (1970). Student's thinking. Education Publishing House.

Thai Duy Tuyen (2008a). Basic issues of Modern Education. Education Publishing House.

Thai Duy Tuyen (2008b). Traditional and Innovative Teaching Methods. Education Publishing House.

Tran Ba Hoanh (2002). The characteristics of active teaching methods. Vietnam Journal of Education, 32, $26-27$. 